\title{
Spectrally selective reflector surfaces for heat reduction in concentrator solar cells: modeling and applications of $\mathrm{TiO}_{2}: \mathrm{Nb}$-based thin films
}

\author{
Christopher M. Maghanga, ${ }^{1,2, \star}$ Gunnar A. Niklasson, ${ }^{1}$ \\ Claes G. Granqvist, ${ }^{1}$ and Mghendi Mwamburi ${ }^{3}$ \\ 'Department of Engineering Sciences, The Ångström Laboratory, Uppsala University, \\ P.O. Box 534, SE-75121 Uppsala, Sweden \\ ${ }^{2}$ Permanent address: Kabarak University, Department of Mathematics and Computing Sciences, \\ P.O. Private Bag 20157, Kabarak, Kenya \\ ${ }^{3}$ Physics Department, Moi University, P.O. Box 1125, Eldoret, Kenya \\ ${ }^{*}$ Corresponding author: c.maghanga@yahoo.com \\ Received 28 February 2011; accepted 25 April 2011; \\ posted 6 May 2011 (Doc. ID 143258); published 29 June 2011
}

\begin{abstract}
The energy conversion efficiency of a conventional $p n$ junction solar cell decreases as the temperature increases, and this may eventually lead to failures in the photovoltaic system, especially if it uses concentrated solar radiation. In this work, we show that spectrally selective reflector (SSR) surfaces can be important for reducing the heat buildup on passively cooled solar cells. We outline a computational scheme for optimizing DC magnetron-sputtered $\mathrm{TiO}_{2}$ :Nb-based SSRs tailored for silicon solar cells and find good agreement of the reflectance with an experimental realization of the optimal SSR. A figure of merit for SSRs has also been derived and applied to the experimental data. (C) 2011 Optical Society of America

OCIS codes: $\quad 310.3840,310.4165,310.6188,310.6805,310.6860,310.7005$.
\end{abstract}

\section{Introduction}

It is well known that the energy conversion efficiency of $p n$ junction solar cells decreases as their temperature increases [1], and elevated temperatures may also have detrimental effects on other components of photovoltaic (PV) systems and lead to thermal stress, which may result in failures. High solar cell temperatures are particularly serious for concentrating solar cell systems, and cooling is then necessary. Different cooling strategies have been reviewed recently [2], and it was found that passive cooling has a large potential in cases where coproduction of hot

0003-6935/11/193296-07\$15.00/0

(C) 2011 Optical Society of America water is not desirable or economically viable. Min et al. showed that a large heat sink area, approximately equal to the concentration ratio times the cell area, would be needed in order to keep the cell temperature at $50{ }^{\circ} \mathrm{C}$ [3]. Surfaces of this size may be unwieldy or simply not available, and alternatives are important. One of these is offered by spectrally selective reflectors (SSRs), whose ideal integrated reflectance is unity below the wavelength corresponding to the bandgap of the absorber $\left(\lambda_{c}\right)$ and zero for $\lambda>\lambda_{c}$ [4-9]. By integrating selective reflection of the radiation with known conventional radiative and convective cooling techniques $[\underline{2}, \underline{3}, \underline{10}, \underline{11}]$, the heat buildup on solar cells can be further reduced, thus cutting back on the temperature-induced drop of the efficiency of the cells. Jiang et al. have proposed a 
similar optical system for combined PV and photothermal conversion by using a spectral beamsplitting filter [12]. Despite the fact that a number of papers on SSR coatings have been published, it appears that their effect on solar cell performance has not been previously assessed.

SSRs can be devised by overcoating reflecting layers with transparent conducting films. Our initial work used $\mathrm{SnO}_{x}: \mathrm{F}$ [4-7], and more recently we have investigated $\mathrm{SSRs}_{\mathrm{s}}$ based on anatase $\mathrm{TiO}_{2}: \mathrm{Nb}[\underline{8}, \underline{9}]$. This latter material was discovered as lately as 2005 [13] and has attracted much interest recently as a high-performance low-cost transparent conductor [14-18]. Our earlier work demonstrated that $\mathrm{TiO}_{2}: \overline{\mathrm{Nb}}$ backed by $\mathrm{Al}$ leads to a reflector with pronounced optical selectivity $[8,9]$. Specifically, the experimental integrated reflectance was $77 \%$ and $28 \%$ in the ranges $300<\lambda<1100 \mathrm{~nm}$ and $1100<$ $\lambda<2500 \mathrm{~nm}$, respectively, for a $\mathrm{TiO}_{2}: \mathrm{Nb}$ film containing 3.7 at. \% of $\mathrm{Nb}$. We also showed that, in order to fabricate a good $\mathrm{TiO}_{2}: \mathrm{Nb}$-based $\mathrm{SSR}$ on $\mathrm{Al}$, an intermediate dielectric layer of $\mathrm{Al}_{2} \mathrm{O}_{3}$ is required to suppress the deep interference fringes that would otherwise compromise the selectivity of the surface $[6,7]$.

The purpose of the present paper is twofold. First, we perform heat balance calculations for concentrating solar cell systems in order to evaluate the effect of the SSR technology on cell efficiency. We find that the use of an SSR material makes a contribution toward lowering the temperature of the concentrator PV cells and may have a niche for systems employing compound parabolic concentrators with concentration ratios up to a factor of ten. Second, we outline a methodology for optimizing the properties of SSR coatings. We analyze the dependence of the optical properties of $\mathrm{TiO}_{2}: \mathrm{Nb}$ coatings on the film thicknesses of the active layer and an intermediate alumina layer. We also derive a figure of merit for SSRs and apply it to our experimental results.

\section{Solar Cell Efficiency and Operating Temperature}

\section{A. Ideal SSR}

The ideal properties of an SSR for use with crystalline silicon solar cells are shown in Fig. 1 . The wavelength $\lambda_{c}$ for switching from high to low reflectance lies at $1100 \mathrm{~nm}$ and corresponds to the silicon bandgap. $R_{\text {cell }}$ and $R_{\text {therm }}$ are the integrated reflectance values, which for a Si solar cell, are given by

$$
\begin{gathered}
R_{\text {cell }}=\frac{\int_{300}^{1100} G(\lambda) R(\lambda) \mathrm{d} \lambda}{\int_{300}^{1100} G(\lambda) \mathrm{d} \lambda}, \\
R_{\text {therm }}=\frac{\int_{1100}^{2500} G(\lambda) R(\lambda) \mathrm{d} \lambda}{\int_{1100}^{2500} G(\lambda) \mathrm{d} \lambda},
\end{gathered}
$$

where $G(\lambda)$ is the air mass (AM) 1.5 solar spectrum [19]. For an SSR with ideal properties, $R_{\text {cell }}=1$ and $\overline{R_{\text {therm }}}=0$ will ensure that solar radiation in the

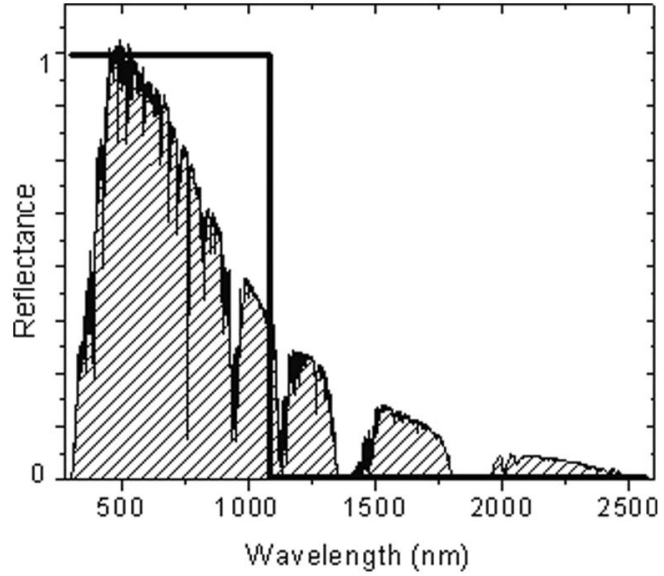

Fig. 1. Ideal spectral reflectance of an SSR appropriate for use with a silicon solar cell. A normalized AM 1.5 solar spectrum is included (shaded).

range $300<\lambda<1100 \mathrm{~nm}$ is reflected toward the solar cell while the rest is absorbed by the SSR and hence does not contribute to the heating of the solar cell.

\section{B. Solar Cell Efficiency}

The dependence of solar cell efficiency $\eta$ is often approximated by a linear relation $[\underline{20}, \underline{21}]$ according to

$$
\eta=\eta_{\mathrm{ref}}\left[1-\beta\left(\tau-\tau_{0}\right)\right],
$$

where $\eta_{\text {ref }}$ is the efficiency at a PV cell temperature $\tau_{0}$ corresponding to the ambient $\left(25^{\circ} \mathrm{C}\right)$, and when the solar irradiance on the cell is equal to $1000 \mathrm{Wm}^{-2}, \beta$ is the temperature coefficient of efficiency, and $\tau$ is the PV cell temperature. In this paper we consider the most common solar cells, namely those made of crystalline $\mathrm{Si}$, which are characterized by $\beta \sim$ $0.005 \mathrm{~K}^{-1}[21]$.

\section{Heat Balance of Solar Cells}

The operating temperature can be estimated from the energy balance equation for a concentrator solar cell, which in our case can be expressed as

$$
\begin{aligned}
& R \alpha A_{0} C q_{0}-\eta R \alpha A_{0} C q_{0}-A_{r} \varepsilon \sigma_{B}\left(\tau^{4}-\tau_{0}^{4}\right) \\
& \quad-A_{c} h\left(\tau-\tau_{0}\right)=0,
\end{aligned}
$$

where the first term denotes the solar power reflected to the cell from mirrors with solar reflectance $R$. Here the cell's surface absorptivity is denoted $\alpha$, the cell area is $A_{0}$, the geometric concentration ratio is $C$, and the solar energy density is $q_{0}$. The second term in Eq. (4) is the electric power delivered to the external load with conversion efficiency $\eta$; it should be noted that the efficiency is defined with respect to the total absorbed solar power. The third term represents the power dissipated through radiation from the surface area $A_{r}$ with surface emissivity $\varepsilon$ where the Stefan-Boltzmann constant is denoted $\sigma_{B}$. The last term, finally, characterizes the power dissipated 
through convection, which depends on the surface area $A_{c}$ and the convective heat transfer coefficient $h$.

If the reflector material in the concentrator cell has SSR properties, the cell absorbs only the useful radiation, i.e., energy corresponding to the wavelengths $\lambda<\lambda_{c}$, while in the absence of the SSR property the wavelength range of absorption spans the whole solar spectrum, say $300<\lambda<2550 \mathrm{~nm}$. Therefore, we express the general heat balance equation in terms of contributions from the radiation below and above $\lambda_{c}$ as

$$
\begin{aligned}
& R_{\text {cell }} \alpha A_{0} C q_{\text {cell }}(1-\eta)+R_{\text {therm }} \alpha A_{0} C q_{\text {therm }}(1-\eta) \\
& \quad-A_{r} \varepsilon \sigma_{B}\left(\tau^{4}-\tau_{0}^{4}\right)-A_{c} h\left(\tau-\tau_{0}\right)=0
\end{aligned}
$$

where $q_{\text {cell }}$ and $q_{\text {therm }}$ are the energy densities in the ranges $300<\lambda<1100 \mathrm{~nm}$ and $1100<\lambda<2500 \mathrm{~nm}$, respectively. They can be estimated from the solar irradiation data [19] as being approximately $0.8 q_{0}$ and $0.2 q_{0}$, respectively. For a reflector with ideal SSR properties according to Fig. 1 , one finds

$$
\begin{aligned}
& R_{\text {cell }} \alpha A_{0} C q_{\text {cell }}(1-\eta)+A_{r} \varepsilon \sigma_{B}\left(\tau^{4}-\tau_{0}^{4}\right) \\
& \quad-A_{c} h\left(\tau-\tau_{0}\right)=0 .
\end{aligned}
$$

Table 1 contains the parameter values used in our model calculations. The absorptivity of the solar cell varies with wavelength and also depends on surface engineering and can be as high as 0.95 [22]. Even in the long wavelength region below the bandgap, a $\mathrm{Si}$ solar cell can have an absorptivity of the order of 0.8 [22]. For simplicity, we used an average value of 0.85 in our calculations as in [3] for the entire solar wavelength range, and for the convective heat transfer coefficient, we also take the value given by Min et al. [3]. Employing the parameters in Table 1 in Eq. (6), we computed the solar cell temperature as a function of concentration for a solar cell with and without an SSR. The results are plotted in Fig. 2 for two different cases. At low geometric concentration, the cell temperature is low, and the difference in temperature between the two cases is small. However, the effect of the SSR becomes evident as concentration increases, and the temperature of the cell without the SSR is significantly higher than with the SSR.

We now discuss two possible cases where SSR coatings may be useful. First we consider a compound parabolic concentrator of the type depicted in Fig. $\underline{3}$.

Table 1. Parameters Used in Calculations of Solar Cell Temperature

\begin{tabular}{lcc}
\hline Parameter & Description & Value \\
\hline$\alpha$ & Surface absorptivity of the cell & 0.85 \\
$\eta$ & Efficiency of the cell & 0.2 \\
$\tau_{0}$ & Ambient temperature & $300 \mathrm{~K}$ \\
$H$ & Convective heat transfer & $5 \mathrm{~W} / \mathrm{m}^{2} \mathrm{~K}$ \\
$C$ & Concentration factor & Variable \\
$\varepsilon$ & Emissivity of the cell & 0.85 \\
\hline
\end{tabular}
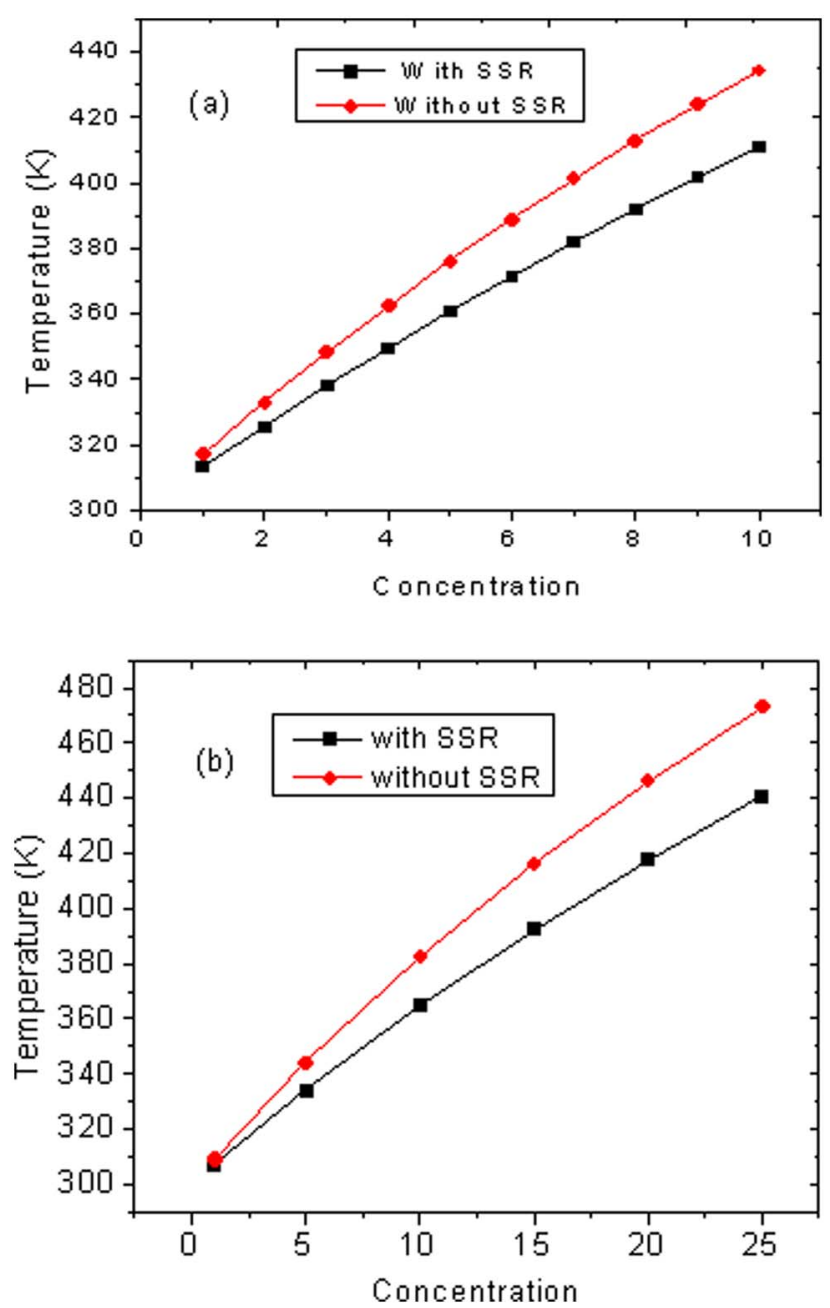

Fig. 2. (Color online) Solar cell temperature versus concentration calculated for constructions with and without SSR for (a) $A_{r}=$ $A_{c}=4 A_{0}$, (b) $A_{r}=4 A_{0}$ and $A_{c}=10 A_{0}$.

This design has a low concentration of $\sim 2$ to 5 . We consider the case of minimum extra passive cooling from convection and radiation by assuming a small convective and radiative area, such that $A_{r}=$ $A_{c}=4 A_{o}$. Figure 2(a) shows that the temperature rise can be kept at 35 to $60^{\circ} \mathrm{C}$ above the ambient if an SSR is used. In order to lower the temperatures further, radiative and convective cooling can be

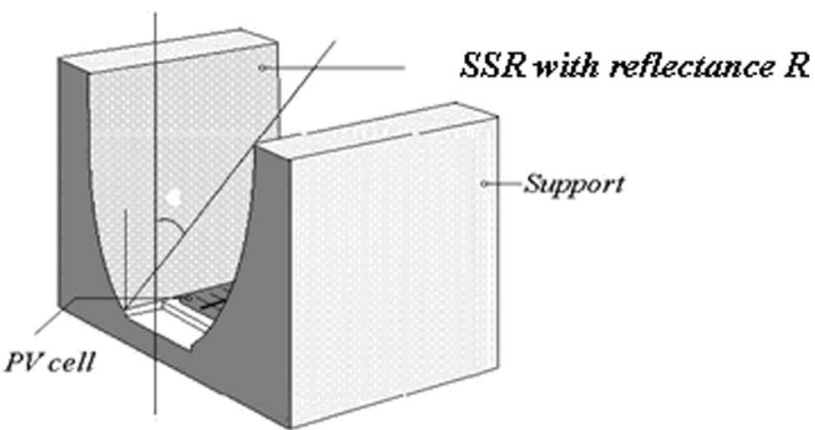

Fig. 3. Integration of an SSR surface and a PV cell in a compound parabolic concentrator. 
enhanced by increasing the convective and radiative surface areas. However, the temperatures mentioned above correspond to reasonable cell efficiencies of $14 \%$ to $16.5 \%$, given an efficiency of $20 \%$ at ambient temperature as in our example. It is, however, more interesting to consider the gain in efficiency that is attainable by using an SSR. In the concentration range that we consider, the temperature is lowered by $10^{\circ} \mathrm{C}$ to $20^{\circ} \mathrm{C}$ when an SSR is used, which leads to efficiency gains of $0.8 \%$ to $1.8 \%$ for the solar cell. This is certainly not negligible, and whether or not an SSR is of practical interest will probably depend on economic considerations.

Figure 2(b) considers parameters appropriate for a parabolic trough concentrator employing the elaborate passive cooling schemes reviewed by Royne et al. [2]. It is seen that, already at a concentration of 15 , the cell temperature has risen to almost $100^{\circ} \mathrm{C}$ above the ambient, which leads to a cell efficiency of only half the value at ambient temperature. We think that this is not tolerable under most circumstances and that active cooling with $\mathrm{PV} /$ photothermal cogeneration is more appropriate in the case of concentration ratios in this range.

\section{Figure of Merit for SSRs}

For a PV concentrator employing a practical SSR, the heating power is proportional to $R_{\text {cell }} q_{\text {cell }}+$ $R_{\text {therm }} q_{\text {therm }}$, while in the absence of an SSR we assume that $R=R_{\text {cell }}$ in the whole solar wavelength range. In the latter case, the heating power is proportional to $R_{\text {cell }} q_{0}$. We now define a dimensionless quantity, which we refer to as a figure of merit (FOM), of an SSR as

$$
\mathrm{FOM}=\frac{R_{\text {cell }} q_{\text {cell }}+R_{\text {therm }} q_{\text {therm }}}{R_{\text {cell }} q_{0}} \approx 0.8+0.2 \frac{R_{\text {therm }}}{R_{\text {cell }}} .
$$

The FOM attains a minimum value of 0.8 for an ideal SSR and should approach this value as closely as possible for real SSR coatings. For a nonselective reflecting surface, the FOM is equal to 1.0.

\section{Experiments and Calculations}

Thin films of $\mathrm{TiO}_{2}: \mathrm{Nb}$ were made by dual-target reactive $\mathrm{DC}$ magnetron sputtering in an $\mathrm{Ar}+\mathrm{O}_{2}$ plasma onto substrates of alumina-coated $\mathrm{Al}$ and of $\mathrm{Si}$, following procedures described elsewhere $[9,14]$. Doping of $\mathrm{TiO}_{2}$ with $\mathrm{Nb}$ was achieved by setting the Ti target power at a constant value and varying the $\mathrm{Nb}$ target power. A small amount of $\mathrm{H}_{2}$ was added to the sputter plasma in order to avoid target poisoning and allow stable sputtering conditions $[23,24]$. The compositions of $\mathrm{TiO}_{2}: \mathrm{Nb}$ films backed by Si were determined by ion beam techniques in the range of atomic weights from $1(\mathrm{H})$ to $41(\mathrm{Nb})$. Rutherford backscattering spectrometry and timeof-flight elastic recoil detection analysis were employed using facilities of the Uppsala University Tandem Laboratory. Spectral normal transmittance
$T(\lambda)$ and near-normal reflectance $R(\lambda)$ were measured in the $300<\lambda<2500 \mathrm{~nm}$ range by use of a Perkin-Elmer Lambda 900 double-beam spectrophotometer equipped with an integrating sphere. A barium sulfate film served as reflectance standard. The results of the film composition and of the spectrophotometric data analysis for obtaining optical constants have been presented elsewhere [14].

The optical properties of the SSRs were modeled using the characteristic matrix formalism for an assembly of thin films $[25,26]$. For light of wavelength $\lambda$ incident on an assembly of $N$ layers, the characteristic matrix is the product of individual matrices for each interface, $I_{m-1, m}$, and for each layer, $L_{m}$, expressed as

$$
\begin{aligned}
{\left[\begin{array}{l}
E^{+}\left(0^{-}\right) \\
E^{-}\left(0^{-}\right)
\end{array}\right] } & =\left\{\left[\prod_{m=1}^{N} I_{m-1, m} L_{m}\right] I_{N, N+1}\right\}\left[\begin{array}{c}
E^{+}\left(z^{+}\right) \\
0
\end{array}\right] \\
& =\left\{\begin{array}{ll}
S_{11} & S_{12} \\
S_{21} & S_{22}
\end{array}\right\}\left[\begin{array}{c}
E^{+}\left(z^{+}\right) \\
0
\end{array}\right] .
\end{aligned}
$$

Here $E^{+}$and $E^{-}$are the complex amplitudes of forward- and backward-travelling plane waves. The front interface toward air of the assembly is denoted $0^{-}$and the back interface toward the substrate is denoted $z^{+}$. The interface matrix components can be obtained from the Fresnel relations as shown in [26]. The layer matrix is obtained [26] from the phase factor

$$
\delta_{m}=(2 \pi / \lambda) d N_{m} \cos \theta_{m},
$$

where $\theta_{m}$ represents the direction of propagation in the $m$ th layer and can be obtained from the incident angle using Snell's law, $N_{m}=n_{m}+i k_{m}$ is the complex refractive index, and $d$ denotes the layer thickness. The reflectivity amplitude of this assembly may then be found from

$$
r(\theta, \lambda)=E^{-}\left(0^{-}\right) / E^{+}\left(0^{-}\right)=S_{21} / S_{11} .
$$

In our case $m=3,2$, and 1 represent the substrate (Al), a dielectric $\left(\mathrm{Al}_{2} \mathrm{O}_{3}\right)$, and the transparent

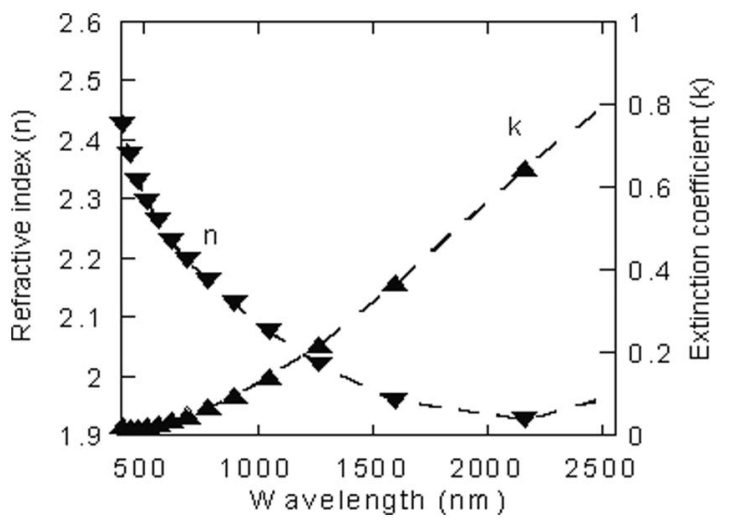

Fig. 4. Optical constants, $n$ and $k$, of an $\mathrm{Nb}^{2} \mathrm{TiO}_{2}$ film containing 3.7 at. \% Nb, from [9]. 
conducting oxide $\left(\mathrm{TiO}_{2}: \mathrm{Nb}\right)$ layer, respectively. Literature data for the optical constants of $\mathrm{Al}$ [27] and $\mathrm{Al}_{2} \mathrm{O}_{3}$ [28] were employed in our calculations. The $\mathrm{Al}_{2} \mathrm{O}_{3}$ is an intermediate oxide layer that was used to suppress strong optical interference effects [6-8]. It has been shown before that a $\mathrm{TiO}_{2}: \mathrm{Nb}$ film containing 3.7 at. \% $\mathrm{Nb}$ exhibits very good selective reflectance [9] and is close to the optimum composition [8]. The optical constants for this material, from $[\underline{9}, 14]$, are shown in Fig. $\underline{4}$ and were used in our model calculations.

\section{Results}

\section{A. Calculated Reflectance}

Figure $\underline{5}$ illustrates the roles of the $\mathrm{Al}_{2} \mathrm{O}_{3}$ and $\mathrm{TiO}_{2}: \mathrm{Nb}$ layer thicknesses on the reflectance. It is found that the layer thicknesses influence both the wavelength at which the reflectance is at a minimum
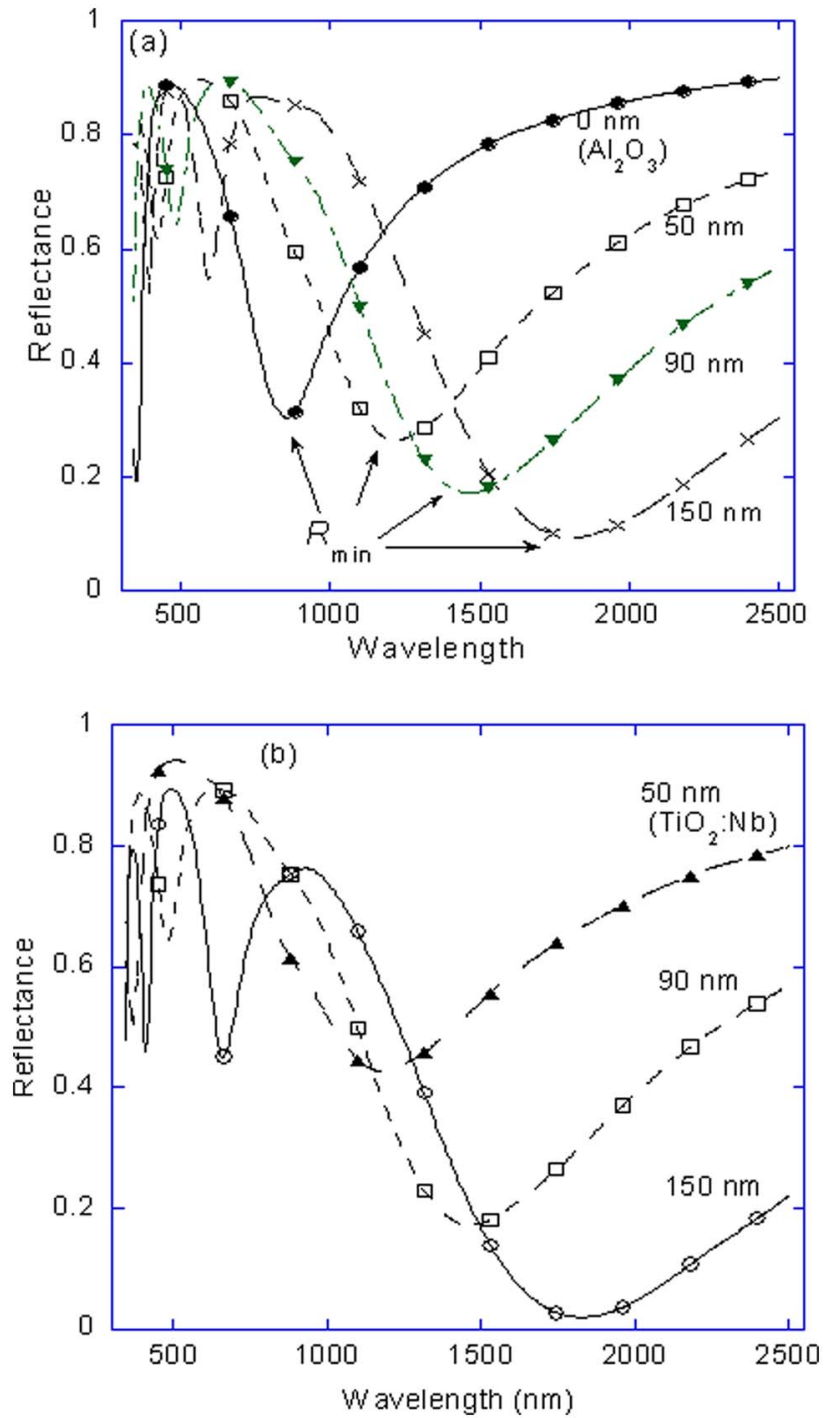

Fig. 5. (Color online) Calculated influence of the thickness of (a) the $\mathrm{Al}_{2} \mathrm{O}_{3}$ layer and (b) the $\mathrm{TiO}_{2}: \mathrm{Nb}$ film on the normal spectral reflectance of $\mathrm{TiO}_{2}: \mathrm{Nb} / \mathrm{Al}_{2} \mathrm{O}_{3} / \mathrm{Al}$ SSRs. In (a) the thickness of the $\mathrm{TiO}_{2}: \mathrm{Nb}$ film is $90 \mathrm{~nm}$, while in (b) the $\mathrm{Al}_{2} \mathrm{O}_{3}$ thickness is $90 \mathrm{~nm}$. $\left(\lambda_{\min }\right)$ and the reflectance value at that wavelength. A shift of $\lambda_{\min }$ to longer wavelengths occurs with increasing thickness while at the same time the reflectance is lowered. Increasing $\mathrm{TiO}_{2}: \mathrm{Nb}$ film thickness, as demonstrated in Fig. 5(b), enhances interference fringe depth, i.e., the distance between the maxima and minima of an interference fringe, but has the advantage of lowering the reflectance at $\lambda_{\min }$. A shift to longer wavelengths is also seen.

The optimum thicknesses of the $\mathrm{Al}_{2} \mathrm{O}_{3}$ and $\mathrm{TiO}_{2}: \mathrm{Nb}$ layers can be determined from the contour plots in Figs. 6(a) and 6(b). The optimal properties are attained by combining a high value of $R_{\text {cell }}$ with a low value of $R_{\text {therm. }}$. Inspection of the plots indicates that the lowest values of $R_{\text {therm }}$ are achieved for $\mathrm{Al}_{2} \mathrm{O}_{3}$ thicknesses between 60 and $150 \mathrm{~nm}$ and a $\mathrm{TiO}_{2}: \mathrm{Nb}$ thickness exceeding $80 \mathrm{~nm}$. The highest values of $R_{\text {cell }}$, however, require a thickness of $\mathrm{TiO}_{2}: \mathrm{Nb}$
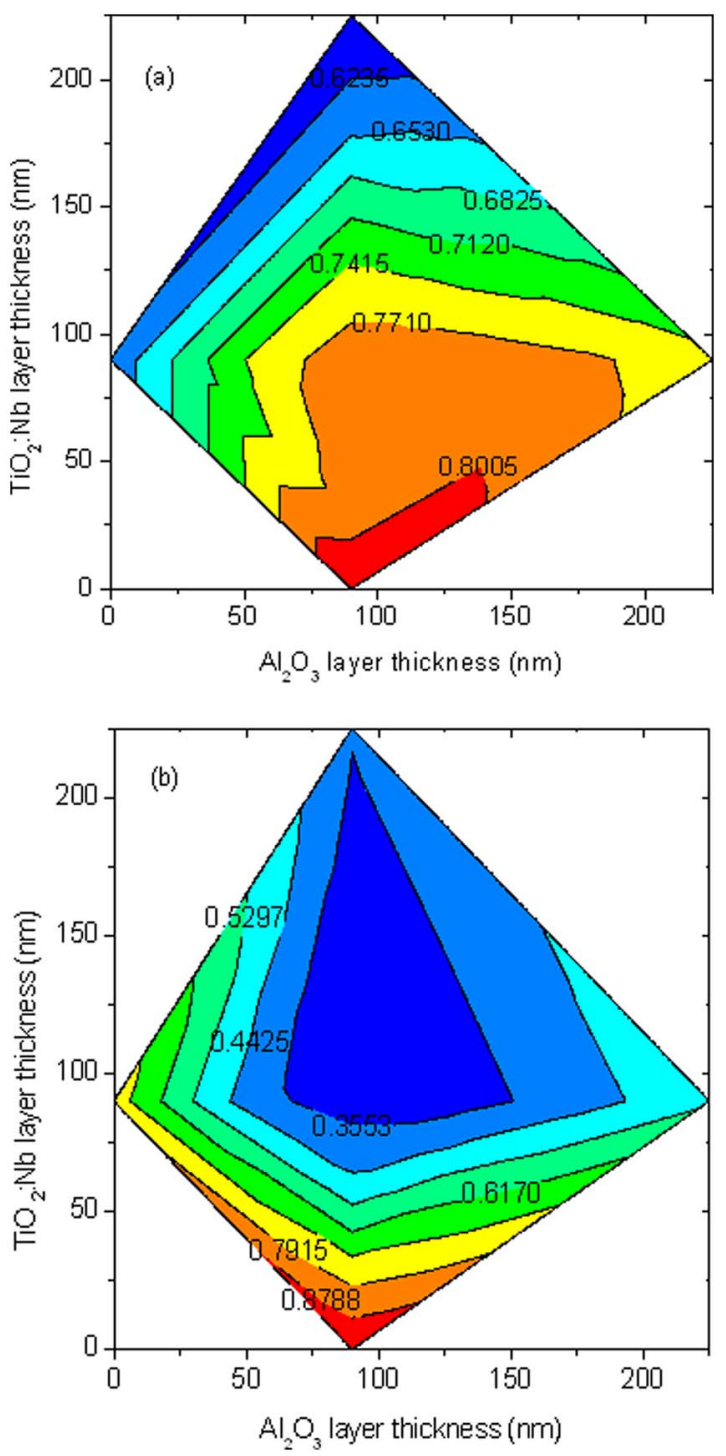

Fig. 6. (Color online) Contour plots showing the variation of (a) $R_{\text {cell }}$ and (b) $R_{\text {therm }}$ as a function of the thicknesses of $\mathrm{TiO}_{2}$ : $\mathrm{Nb}$ and $\mathrm{Al}_{2} \mathrm{O}_{3}$ in a $\mathrm{TiO}_{2}: \mathrm{Nb} / \mathrm{Al}_{2} \mathrm{O}_{3} / \mathrm{Al}$ stack. 

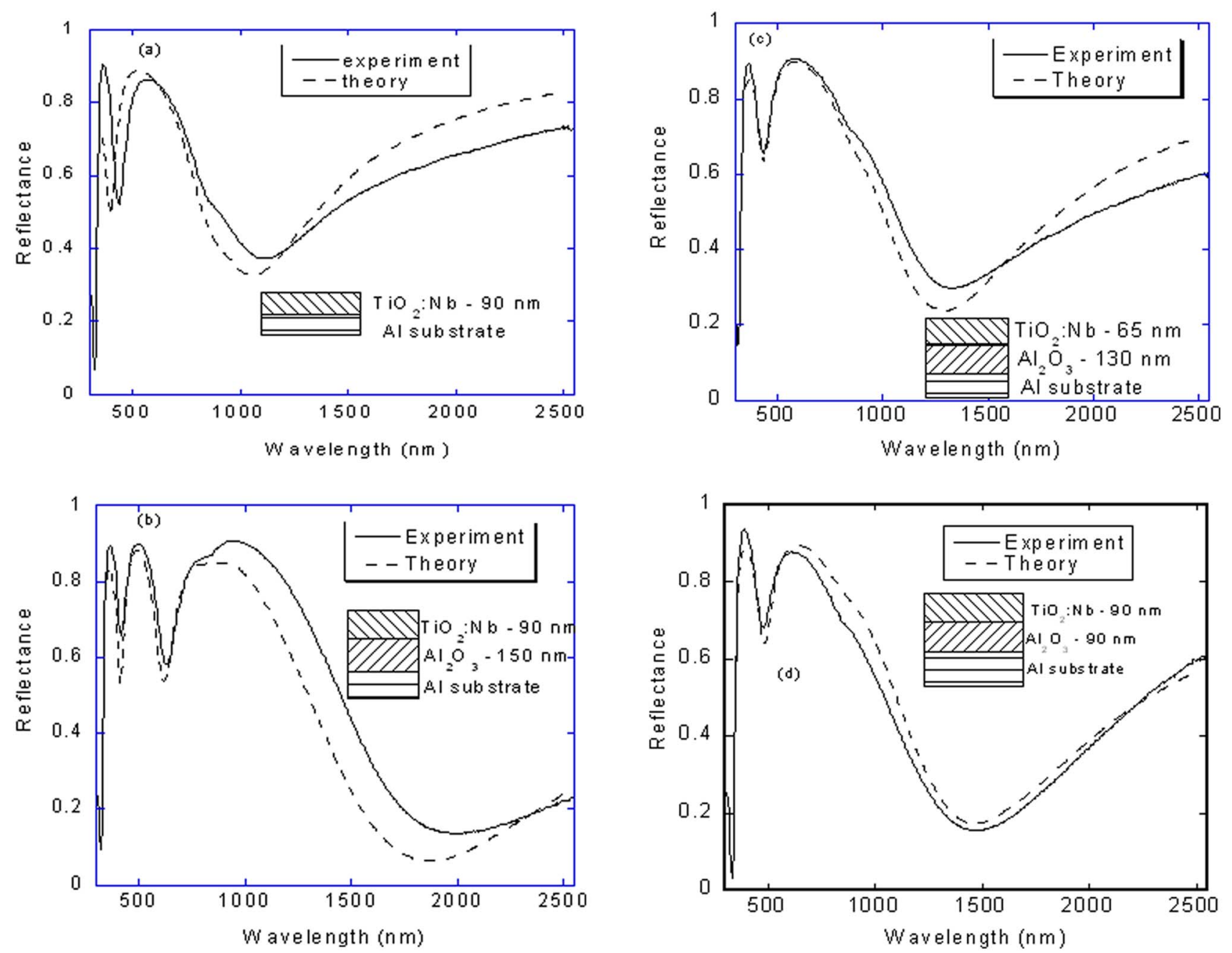

Fig. 7. (Color online) Calculated normal and measured near-normal spectral reflectance for (a) a $\mathrm{TiO}_{2}: \mathrm{Nb}$ film on $\mathrm{Al}$ and for (b), (c), (d) three $\mathrm{TiO}_{2}: \mathrm{Nb} / \mathrm{Al}_{2} \mathrm{O}_{3} / \mathrm{Al}$ structures. The $\mathrm{TiO}_{2}$ films contained 3.7 at. $\% \mathrm{Nb}$. Layer thicknesses are given in the insets.

below $\sim 100 \mathrm{~nm}$, and thus we have determined a rather narrow optimal region.

\section{B. Experimental Data}

Figure 7 shows a comparison between calculated and experimental data for a number of SSR thin film structures based on $\mathrm{TiO}_{2}: \mathrm{Nb}$ films. Figure 7 (a) depicts the inferior performance of an SSR without the $\mathrm{Al}_{2} \mathrm{O}_{3}$ interlayer. Figure 7(c) shows the reflectance of $\mathrm{TiO}_{2}: \mathrm{Nb} / \mathrm{Al}_{2} \mathrm{O}_{3} / \mathrm{Al}$ stacks outside of the optimum region, while Figs. 7(b) and 7(d) illustrate the improved performance that was obtained by choosing film thicknesses within the optimal region established from Fig. $\underline{6}$. Figure $\underline{7}$ shows that, in general,

Table 2. FOM Based on the Experimental Data for SSR Coatings Shown in Figs. 7(a)-7(d)

\begin{tabular}{llll}
\hline Sample & $R_{\text {cell }}$ & $R_{\text {them }}$ & FOM \\
\hline (a) & 0.686 & 0.512 & 0.94 \\
(b) & 0.802 & 0.496 & 0.92 \\
(c) & 0.782 & 0.387 & 0.90 \\
(d) & 0.756 & 0.280 & 0.87 \\
\hline
\end{tabular}

there was good agreement between calculated and experimental reflectance data. Minor deviations exist, though, which can be attributed to the limited accuracy in determining film thicknesses. In addition, there exists thickness differences of the aluminum oxide layer between the expected and the actual, which are brought about by the oxidation of the $\mathrm{Al}$ substrates and means that, besides the sputtered layer, there can be an additional layer of $\mathrm{Al}_{2} \mathrm{O}_{3}$ that existed before sputtering.

The FOM for the experimental samples is given in Table 2, which shows that the film with $90 \mathrm{~nm}$ of $\mathrm{Al}_{2} \mathrm{O}_{3}$ and $90 \mathrm{~nm}$ of $\mathrm{TiO}_{2}: \mathrm{Nb}$ exhibits the best SSR properties with $\mathrm{FOM}=0.87$, which clearly is not far away from the ideal value of 0.80 .

\section{Conclusion}

We have determined the contribution of an SSR to the heat reduction in a concentrating PV system. It appears that constructions including SSRs may have niche applications in cases where passive cooling of the solar cells is desirable and for concentration factors less than $\sim 10$. The diminished solar cell 
temperature due to the SSR can lead to cell efficiency improvements between 0.01 and 0.02 , which are not insignificant numbers.

We calculated "cell" and near-infrared "thermal" reflectance values of $\mathrm{TiO}_{2}: \mathrm{Nb} / \mathrm{Al}_{2} \mathrm{O}_{3} / \mathrm{Al}$ SSR stacks for varying layer thicknesses. It was shown that the thickness of both $\mathrm{TiO}_{2}: \mathrm{Nb}$ and $\mathrm{Al}_{2} \mathrm{O}_{3}$ play critical roles for optimizing the spectral selectivity of the SSR. The best properties were achieved when the thicknesses of $\mathrm{TiO}_{2}: \mathrm{Nb}$ as well as of $\mathrm{Al}_{2} \mathrm{O}_{3}$ were $\sim 90 \mathrm{~nm}$, which corresponds to the experimental reflectance values $R_{\text {cell }}=0.756$ and $R_{\text {them }}=0.28$.

This work was supported by grants from the Swedish Research Council (VR). One of the authors (C. M. M.) would like to thank the International Science Programme of Uppsala University for a scholarship.

\section{References}

1. J. J. Wysocki and P. Rappaport, "Effect of temperature on photovoltaic solar energy conversion," J. Appl. Phys. 31, 571-578 (1960).

2. A. Royne, C. J. Dey, and D. R. Mills, "Cooling of photovoltaic cells under concentrated illumination: a critical review," Solar Energy Mater. Solar Cells 86, 451-483 (2005).

3. C. Min, C. Nuofu, Y. Xiaoli, W. Yu, B. Yiming, and Z. Xingwang, "Thermal analysis and test for single concentrator solar cells," J. Semiconductors 30, 044011 (2009).

4. M. Mwamburi, E. Wäckelgård, and A. Roos, "Preparation and characterisation of solar selective $\mathrm{SnO}_{x}: \mathrm{F}$ coated aluminium reflector surfaces," Thin Solid Films 374, 1-9 (2000).

5. M. Mwamburi and E. Wäckelgård, "Doped tin oxide coated aluminium solar selective reflector surfaces," Solar Energy 68, 371-378 (2000).

6. M. Mwamburi, E. Wäckelgård, A. Roos, and R. Kivaisi, "Polarization-dependent angular-optical reflectance in solarselective $\mathrm{SnO}_{x}: \mathrm{F} / \mathrm{Al}_{2} \mathrm{O}_{3} / \mathrm{Al}$ reflector surfaces," Appl. Opt. 41, 2428-2434 (2002).

7. M. Mwamburi, A. Hoel, and E. Wäckelgård, "Surface morphologies of spectrally selective and polarization-dependent angular optical reflectors of $\mathrm{SnO}_{x}: \mathrm{F}$-coated anodized aluminum," Solar Energy Mater. Solar Cells 84, 381-394 (2004).

8. C. M. Maghanga, G. A. Niklasson, C. G. Granqvist, and M. Mwamburi, "Optical modeling of spectrally selective reflectors based on $\mathrm{TiO}_{2}: \mathrm{Nb}$ transparent conducting oxide films for silicon solar cell applications," Proc. SPIE 7407F, 74070F (2009).

9. C. M. Maghanga, J. Jensen, G. A. Niklasson, C. G. Granqvist, and M. Mwamburi, "Transparent and conducting $\mathrm{TiO}_{2}: \mathrm{Nb}$ films made by sputter deposition: application to spectrally selective solar reflectors," Solar Energy Mater. Solar Cells 94, 75-79 (2010).

10. M. W. Edenburn, "Active and passive cooling for concentrating photovoltaic arrays," in Proceedings of the 14th IEEE Photovoltaic Specialists Conference (IEEE, 1980), pp. 771-776.
11. A. Cheknane, B. Benyoucef, and A. Chaker, "Performance of concentrator solar cells with passive cooling," Semicond. Sci. Technol. 21, 144-147 (2006).

12. S. Jiang, P. Hu, S. Mo, and Z. Chen, "Optical modeling for a two-stage parabolic trough concentrating photovoltaic/ thermal system using spectral beam splitting technology," Solar Energy Mater. Solar Cells 94, 1686-1696 (2010).

13. Y. Furubayashi, T. Hitosugi, Y. Yamamoto, K. Inaba, G. Kinoda, Y. Hirose, T. Shimada, and T. Hasegawa, "A transparent metal: Nb-doped anatase $\mathrm{TiO}_{2}$," Appl. Phys. Lett. 86, 252101 (2005).

14. C. M. Maghanga, G. A. Niklasson, and C. G. Granqvist, "Optical properties of sputter deposited transparent and conducting $\mathrm{TiO}_{2}$ :Nb films," Thin Solid Films 518, 1254-1258 (2009).

15. M. S. Dabney, M. F. A. M. van Hest, C. W. Teplin, S. P. Arenkiel, J. D. Perkins, and D. S. Ginley, "Pulsed laser deposited Nb doped $\mathrm{TiO}_{2}$ as a transparent conducting oxide," Thin Solid Films 516, 4133-4138 (2008).

16. N. Yamada, T. Hitosugi, J. Kasai, N. L. H. Hoang, S. Nakao, Y. Hirose, T. Shimada, and T. Hasegawa, "Direct growth of transparent conducting $\mathrm{Nb}$-doped anatase $\mathrm{TiO}_{2}$ polycrystalline films on glass," J. Appl. Phys. 105, 123702 (2009).

17. T. Hitosugi, N. Yamada, S. Nakao, Y. Hirose, and T. Hasegawa, "Properties of $\mathrm{TiO}_{2}$-based transparent conducting oxides," Phys. Status Solidi A 207, 1529-1537 (2010).

18. Y. Sato, Y. Sanno, C. Tasaki, N. Oka, T. Kamiyama, and Y. Shigesato, "Electrical and optical properties of $\mathrm{Nb}$-doped $\mathrm{TiO}_{2}$ films deposited by dc magnetron sputtering using slightly reduced $\mathrm{Nb}$-doped $\mathrm{TiO}_{2-x}$ ceramic targets," J. Vac. Sci. Technol. A 28, 851-855 (2010).

19. http://rredc.nrel.gov/solar/spectra/am1.5.

20. D. Meneses-Rodríguez, P. P. Horley, J. González-Hernández, Y. V. Vorobiev, and P. N. Gorley, "Photovoltaic solar cells performance at elevated temperatures," Solar Energy 78, 243-250 (2005).

21. M. Mattei, G. Notton, C. Cristofari, M. Muselli, and P. Poggi, "Calculation of the polycrystalline PV module temperature using a simple method of energy balance," Renew. Energy 31, 553-567 (2006).

22. M. Brogren, P. Nostell, and B. Karlsson, "Optical efficiency of a PV-thermal hybrid CPC module for high latitudes," Solar Energy 69, 173-185 (2001).

23. V. Ondok and J. Musil, "Effect of hydrogen on reactive sputtering of transparent oxide films," Plasma Processes Polym. 4, S319-S324 (2007).

24. J. Musil, P. Baroch, J. Vlček, K. H. Nam, and J. G. Han, "Reactive magnetron sputtering of thin films: present status and trends," Thin Solid Films 475, 208-218 (2005).

25. Z. Knittel, Optics of Thin Films (Wiley, 1976), pp. 40-46.

26. R. M. A. Azzam and N. M. Bashara, Ellipsometry and Polarized Light (North-Holland, 1987), pp. 332-340.

27. D. Y. Smith, E. Shiles, and M. Inokuti, "The optical properties of metallic aluminum," in Handbook of Optical Constants of Solids, E. D. Palik, ed. (Academic, 1985), pp. 389-406.

28. T. S. Eriksson, A. Hjortsberg, G. A. Niklasson, and C. G. Granqvist, "Infrared optical properties of evaporated alumina films," Appl. Opt. 20, 2742-2746 (1981). 